\title{
MIRADAS SOBRE EL «DESASTRE». APROXIMACIÓN A CIEN AÑOS DE HISTORIA DEL NOVENTA Y OCHO
}

\author{
Carlos Gil Andrés
}

“Todavía el 98!" Esta frase no corresponde a nuestros días ni tiene que ver con la abundante nómina de publicaciones que salen a la luz con motivo del centenario del «Desastre» de 1898. Se debe a la pluma de Manuel Azaña y es el título de un artículo aparecido en 1930 a propósito de la inauguración en Cartagena de un cenotafio en memoria de las víctimas caidas en las batallas navales de Cavite y Santiago de Cuba. Como un signo del cambio de los tiempos el embajador de los Estados Unidos, representante de los antiguos enemigos, deposita una corona de flores en la ceremonia. Las páginas que siguen pretenden presentar la herencia del 98 a través de los libros escritos sobre el "desastre" en tres momentos bien diferentes y significativos: los años de la guerra y del fin de siglo en primer lugar, la década inicial de la dictadura franquista en segundo término y, por último, un breve e incompleto estado de la cuestión en las cercanías del centenario.

Un tercio de siglo después de la pérdida de Cuba, Puerto Rico y Filipinas, las últimas colonias que recordaban lo que había sido el imperio español en otros tiempos, el que luego fuera Presidente de la Segunda República española critica el patrioterismo triunfalista de los primeros momentos de la guerra y los ecos que todavía se pueden escuchar de la vana y estéril palabrería que destilan escritores y políticos una vez consumada la derrota:

"El ánimo público se rebajó hasta dar la bienvenida a las desgracias, mirándolas como un garrotazo formidable que nos sacudía la Providencia para que avivásemos el seso. De una conmoción tan fuerte, que al parecer removió lo más hondo de nuestro espíritu adolescente, sólo queda una memoria afligida (...) Puestos a recordar debiéramos recordarlo todo, o lo más posible. Por de pronto, los acentos, los aullidos del vendaval que sobre nosotros estuvo soplando"1. 
Por encima del fatuo nacionalismo, del aturdimiento y del "vocerío garrulo" nuestro autor rescata sólo algunas voces inteligentes y sensatas como las de Unamuno o Pi y Margall. Del resto, incluyendo el desbordante caudal de literatura regeneracionista de los años siguientes, poco se puede salvar como no sea la retórica pesimista y lastimera:

\footnotetext{
"Notemos, por su generalidad, cierto rasgo en la reacción sentimental que sucedió al Desastre: es el desencanto, la desilusión, el chasco. Parecía que los españoles vomitaban las ruedas de molino que durante siglos estuvieron tragando" 2 .
}

ENtre ia «Marcha» de Cadiz y el coro de Repatriados de Gigantes y Cabezudos

La imagen del brusco despertar de un sueño secular se repite en buena parte de la literatura publicada en los días inmediatos de la derrota. El funesto y breve enfrentamiento bélico entre España y los Estados Unidos es el aldabonazo que sacude las conciencias de los políticos, militares, intelectuales y escritores españoles, mostrando la triste realidad de una nación de tercer orden dentro el escenario mundial:

"Desempeñamos el papel de desdichado caminante que marcha desconfiado y tranquilo por un bosque inculto e impenetrable, $y$ de improviso es asaltado por una cuadrilla de bandidos armados hasta los dientes, que le atacan por todos los lados para robarle, y después de corta lucha, lo consiguen, dejando al infeliz arruinado y cubierto de heridas, por las que amenaza escaparse presurosa la existencia" ${ }^{3}$.

Sorpresa y desengaño en los primeros momentos; indignación y búsqueda de responsabilidades posteriormente. En las páginas del texto citado se rehabilita al Ejército, única institución sana en medio de la podredumbre que todo lo invade, y se arremete contra la débil y vacilante política de los gobiernos, confabulados con la mayoría de la prensa para mantener engañada a la opinión pública sobre la realidad del conflicto. Y mientras tanto el pueblo, indiferente y apático, demasiado ignorante y falto de energías para reaccionar y protestar, permanece más preocupado por el último estreno teatral o la próxima corrida de toros que por la suerte de las posesiones de Ultramar. Estas opiniones se repiten en buena parte de las crónicas que abordan el relato del "desastre" y pretenden indagar las causas y apuntar culpables.

Sin embargo, durante la guerra, antes de que arriben a la península las noticias de las humillantes derrotas, pocos avisos de lo que podía pasar encontramos si exceptuamos las solitarias voces apuntadas por Azaña de personalidades como Pi y Margall o Unamuno, los sensatos comentarios de Clarín o las críticas matizadas aunque no antibelicistas de Blasco Ibáñez ${ }^{4}$. Discursos, arengas y proclamas patrióticas ocupan las tribunas políticas y las columnas de los periódicos aunando esfuerzos para elevar el espíritu guerrero y favorecer la suerte de los bravos soldados españoles. La Iglesia no

2. Ibid., p. 271.

3. MESA DE LA PEÑA, R. España. Notas político-militares, Madrid, 1899, p. 32

4. Artículos publicados por Francisco PI Y MARGALL en El Nuevo Régimen (ver Articles, Barcelona, 1908); Miguel de UNAMUNO, Paz en la Guerra, en Obras Completas, Madrid, 1951, vol. II; Yvan LISSORGUES, Clarín político, Toulouse, 1980, 2 vols.; y Vicente BLASCO IBÁÑEZ, Contra la Restauración. Periodismo político 1895-1904, Bilbao, Nuestra Cultura, 1978. 
sólo no es ajena a este espíritu de exaltación bélica, sino que en buena parte es protagonista a través de las exhortaciones de los obispos y los sermones de los párrocos a los feligreses. El presbítero Juan Bautista Casas escribe desde La Habana contra los separatistas cubanos llamando a la lucha para reverdecer los pasados laureles de los soldados españoles:

"Prescindan de las miserias de partido, levántense de las pequeñeces humanas que los gastan e inutilizan para empresas grandes, busquen enseñanzas provechosas en nuestra historia nacional, pidan consejo y dirección a varones según el corazón de Dios (...) y así unidos, ilustrados y dirigidos sofocarán la locura de los separatistas y anexionistas cubanos, inspirarán respeto, y si es necesario, impondrán el merecido castigo a la nación desleal y absorbente que los apoya, y obrando de este modo aumentarán el esplendor de la Patria y de la Monarquía. ¡Viva España! ¡Viva Cuba española!"s.

Cuando la guerra se alarga y surge la posibilidad de un enfrentamiento con los Estados Unidos se incrementa el caudal de publicaciones con este elevado tono patriótico. En ellas se denuncian los bárbaros procedimientos empleados por los insurrectos y se subraya la falsedad de "laborantes y corresponsales, la mala fe de la prensa y los políticos yankees" "Inútil ya la palabrería de embajadores y diplomáticos que no pueden contener la indignación popular: "los aceros saltarán de la vaina y vendrá la guerra". Una guerra que se acepta sin miedo como la única salida honrosa frente a tantas afrentas de los norteamericanos, ignorantes del enemigo al que se enfrentan:

“QQueréis poseer Cuba? Pues venid a tomarla. El débil español del siglo XIX piensa como pensaban sus abuelos en el siglo XVI, y dice hoy lo que ayer decían los grandes conquistadores: Dios hizo el cielo para quien lo merezca y la tierra para quien la gane" obis.

No sabemos si los soldados y marineros españoles fallecidos en Cuba y Filipinas alcanzaron la gloria celeste pero sí que conocemos la rapidez con la que perdieron los territorios que defendían. El paso del fervor patriótico al llanto lastimoso y lacerante por la derrota y la decadencia de la nación se puede seguir a través de los libros aparecidos antes y después del Desastre. Pero no sólo son importantes los abundantes informes, memorias y opúsculos firmados por publicistas y escritores de toda índole, más significativas si cabe pueden ser, por el amplio eco que tenían, obras populares como las zarzuelas, género de moda a finales del siglo XIX. Precisamente La Marcha de Cádiz, el himno oficioso español interpretado en todas las manifestaciones y reuniones patrióticas, procede de Cádiz, una famosa zarzuela estrenada en Madrid en 1886. En sus diálogos, desfiles y cuadros militares aparece reflejado el heroísmo y entusiasmo patriótico de los defensores del último baluarte de la soberanía nacional frente al francés invasor. Cuando las tropas napoleónicas levantan el sitio los soldados españoles se aprestan a combatir al son de los compases de la conocida marcha:

5. Juan BAUTISTA CASAS. La guerra separatista de Cuba. Sus causas, medios de terminarla y de evitar otras, Madrid, 1896.

6. Nota "al público" del traductor del libro de George BRONSON REA, Entre los rebeldes. La verdad de la guerra. Revelaciones de un periodista yankee, Madrid, 1898.

6bis. Adolfo LLANOS Y ALCARAZ, La guerra con los Estados Unidos, La Habana, 1897. 
"Quizá no se haya compuesto pasodoble alguno más brioso, más marcial, más cálido para exaltar el sentimiento patriótico de un pueblo en armas. La presentación del número era de efecto graduado y sorprendente. Los primeros acordes se oían lejanos y en un progresivo "crescendo" de orquesta iba percibiéndose la aproximación de las tropas de voluntarios aragoneses (...) y en el fondo, a lo alto de un fuerte, ondeaba una bandera española. El momento musical del «iViva España!» era emocionante para quien no tuviese del todo adormecidas las fibras patrióticas"”.

En los años de la guerra se representan en Madrid y en los teatros y salsas de toda España un buen número de zarzuelas que contribuyen a elevar el fervor nacionalista de los espectadores mostrando historias de uniformes y tipos de milicia. En El tambor de granaderos se glorifica a los indomables madrileños en los días de la ocupación francesa; en La Espada de bonor la protagonista es una mujer disfrazada de soldado para encubrir a un hermano prófugo- que consigue un premio por su bravura en unas maniobras; los cuadros de Los voluntarios recrean las hazañas de los catalanes que al mando de Prim combatieron en la primera campaña africana; la bizarría y valentía de los oficiales del ejército se retratan en Campanero y sacristán; la indiscutida españolidad de la "perla antillana" se subraya en Cuba Libre; en Los golfos un joven marcha a Cuba como sustituto para aliviar a su familia necesitada; y en La Marcha de Cádiz se juega con los apuros de un alcalde para formar una orquesta que toque los acordes de la celebérrima composición de Chueca ${ }^{8}$.

Las escenas de la guerra de la Independencia se toman como excusa varias veces para destacar el amor a la patria y el sentido del deber y del honor como valores propios del carácter español, indelebles frente a los reveses y las adversidades. Así reza en el final de Trafalgar, zarzuela estrenada en 1890 y representada en innumerables ocasiones, cuando uno de los personajes lanza un mensaje optimista que ocho años después parecerá más un epitafio:

"- Que quizá siglo que empieza
con tan desastrosa ruina,
a la española Marina
reserve un fin de grandeza".

El final de la marina española en aguas de Cavite y Santiago hace que los soldados que marcharon a la guerra acompañados por la "marcha" de Cádiz regresen ahora de manera bien diferente, vencidos y enfermos, imagen que llega también a los escenarios a través del coro de repatriados de la zarzuela Gigantes y Cabezudos. interpreta-

7. José DELEITO Y PIÑUELA, Origen y apogeo del "género chico", Madrid, Revista de Occidente, 1949, pp. 155-156.

8. "La marcha aquí terminó/ si no te parece mal,/ aplaude, lo pido yo,/ por el himno nacional", Celso LUCIO y Enrique GARCÍA ÁlVAREZ, "La Marcha de Cádiz", en La novela cómica, nº 24, 4 de marzo de 1917 (estrenada el 11 de octubre de 1896). Señalamos sólo algunas obras famosas de las 1.500 estrenadas en los teat ros de Madrid entre 1890 y 1900 .Véanse, además del trabajo citado en la nota anterior, los estudios de Matilde MUÑOZ, Historia del Teatro en España, Madrid, Editorial Tesoro, 1965, vol. III (La zarzuela y el género chico), pp. 274-286; Mariano ZURITA, Historia del género chico, Madrid, Prensa Popular, 1920, pp. 67-81 y 117-122; y Serge SALAÜN, "El «género chico» o los mecanismos de un pacto cultural", en El teatro menor en España a partir del siglo XVI, Madrid, C.S.I.C., 1983, pp. 251-261.

9. Origen y apogeo..,Ob. Cit., p. 111. 
da por primera vez en noviembre de $1898^{10}$. El ambiente pesimista de estos momentos se deja notar también en otras obras como El galope de los siglos, donde el autor retrata a un desventurado siglo XIX representado por las figuras de un guardia civil, una gran fábrica y un tranvía eléctrico; algo parecido a lo que vemos en Los presupuestos de Villapierde, parodia crítica sobre la reforma fiscal del Ministro de Hacienda Villaverde en la que el siglo XX aparece en forma de una vistosa joven mientras un viejo caduco personifica al siglo XIX con unos grandes cartelones en los que se lee: "Guerras, déficit, epidemias, huelgas" .

El repaso de lo ocurrido en el pasado reciente en busca de causas que expliquen el "desastre" y la mirada hacia un incierto futuro preñado de problemas y conflictos son los dos temas de reflexión del fin de siglo. Las crónicas publicadas en los años siguientes no difieren mucho en sus comentarios. Se describen los sucesos bélicos aderezados con noticias sobre la situación interior, incluyendo ejemplos de malestar y de protesta, como hace Fernando Soldevilla en sus recopilaciones ${ }^{12}$ o apuntan en sus historias José Ortega Rubio y Antonio Pirala. Pero el discurso más generalizado coincide en señalar dos factores principales: la indiferencia del pueblo frente a la catástrofe y la responsabilidad de los gobernantes que han vendido al país para salvar sus intereses ${ }^{13}$. Varios de los protagonistas de las derrotas como Weyler, Cervera y Polavieja darán también sus propias versiones de lo acontecido para justificar su actuación ${ }^{14}$. Ha llegado la hora de hablar y los militares se ven "tan impopulares en la Nación" que se defienden señalando su papel de víctimas propiciatiorias, la inferioridad de sus fuerzas y la ineptitud de quienes les enviaron a un inútil sacrificio ${ }^{15}$. Los responsables han sido los informantes sin criterio, los "pirotécnicos famosos de la política bullanguera", y los llamados directores "de esta burguesía inconsciente, anémica y vanidosa" que ha conducido al país a la descomposición social y a la "espantosa confusión" en la que se agita ${ }^{16}$.

Junto a estas interpretaciones de aquellos que han tenido puestos de responsabilidad durante el conflicto bélico y ahora se ven apuntados por el dedo acusador disponemos de visiones de representantes de la clase política como el Conde de Romanones o Gabriel Maura ${ }^{17}$, algunas narraciones de testigos presenciales y memo-

10. Miguel ECHEGARAY, "Gigantes y Cabezudos", en La novela cómica, $\mathrm{n}^{\circ}$ 59, Madrid, 27 de enero de 1918.

11. Origen y apogeo..., Ob. Cit., pp. 141 y 309.

12. Fernando SOLDEVILLA, El año político de 1896, Madrid, 1897; El año político de 1897, Madrid, 1898; y el año político de 1898, Madrid, 1899.

13. Juan ORTEGA RUBIO, Historia de la Regencia de María Cristina Habsbourg-Lorena, Madrid, 1906, vol. III; Antonio PIRALA, España y la Regencia. Anales de diez y seis años (1885-1902), Madrid, 1907 , vol. III.

14. Valeriano WEYLER, Mi mando en Cuba (10 de febrero de 1896 a 31 de octubre de 1897). Historia militar y política de la última guerra separatista durante dicho mando, Madrid, 1911, 5 vols; Pascual CERVERA, Guerra Hispano-Americana. Colección de documentos referentes a la Escuadra de Operaciones de las Antillas, El Ferrol, 1899; Marqués de POLAVIEJA, Mi política en Cuba. Lo que ví, lo que bice, lo que anuncié, Madrid, 1898.

15. Carlos SAAVEDRAY MAGDALENA, Alguna observaciones sobre los desastres de la marina española en la guerra con los Estados Unidos, El Ferrol, 1898, pp. 5-14.

16. Luis PÉREZ DE VARGAS, Combate de santiago. La opinión y la Marina, El Ferrol, 1898, pp. 4, 14 у 19.

17. Conde de ROMANONES (Alvaro de Figueroa y Torres), Doña María Cristina Habsburgo Lorena. La discreta regente de España, Madrid, 1934 y Sagasta o el político, Madrid, 1930; Gabriel MAURA GAMAZO, Historia crítica del reinado de Don Alfonso XIII bajo la regencia de doña Maria Cristina de Austria, Barcelona, 1919. 
rias que dedican algún pasaje a los años del conflicto colonial ${ }^{18}$. Ramón y Cajal, por ejemplo, recuerda un "país ignorante y ofuscado", y José Francos Rodríguez dibuja el "hervor" de los males de patria "a cada instante más agudos y desconsoladores"19. Este último autor citado se queja amargamente de que el "desastre" no trajera consigo cambios sustanciales en la vida de la nación:

"(...) no produjo sacudidas hondas, estremecimientos colectivos, ni siquiera alborotos. Nos contentamos con desahogos literarios, dándole a la prosa misión que las sociedades recias cumplen con otras más decididas resoluciones" ${ }^{20}$.

No deja de llevar parte de razón este comentario crítico si observamos la prolija nómina de escritores que pusieron en letras de imprenta sus ideas acerca de cuáles eran los males de la patria y cuáles debían de ser los remedios a aplicar para contribuir a su regeneración. Esta era la palabra clave que se repite desde las tribunas del Congreso de Diputados hasta en el escaparate de una humilde zapatería como ironiza Baroja ${ }^{21}$. Regenerar, volver a nacer, dar un nuevo ser a la nación degenerada y postra$\mathrm{da}$, sin energías físicas ni morales para aventurarse en el siglo XX. Esta es la consigna:

"Qéjense los escépticos a la moda, esos superficiales que presumen de hombres de ciencia y experiencia, del martilleo contínuo con que hiere sus oídos la palabra «regeneración", repetida en las hojas impresas de los periódicos, en revistas, en discursos y libros. Yo soy de los ilusos, de los cándidos, que aun creen en la eficacia de la predicación, persistente, reiterada, tenaz, que, poco a poco, se va metiendo en las conciencias. ¡Ojalá esa palabra se repitiese aún mucho más de lo que se repite! El día en que todos o casi todos la sintamos por dentro, transformada en deseo irresistible, estaremos muy cerca de nuestra redención. Querer ser bueno, es casi serlo ya"22.

Quien así habla es César Silió Cortés. Repite los tópicos de la atonía, la falta de ideales, el letargo de un pueblo que no da señales de existencia y la necesidad de enmienda y redención para que nazca la esperanza en el porvenir y "huya de nosotros el frío de muerte que ha seguido al desastre".Admitida la decadencia de España las pregun-

18. Ver, entre otros, Eloy RECIO FERRERAS, "Diario inédito escrito por un soldado español en la guerra de Cuba, 1896-1899", Revista de Historia de América, 112, 1991, pp. 21-42; Carlos RÍA BAJA, El desastre filipino. Memorias de un prisionero, Barcelona, 1899; Vicente de CORTIJO, Apuntes para la bistoria de la pérdida de muestras colonias por un testigo presencial, Madrid, 1899; y Juan y José TORAL, El sitio de Manila. Memorias de un voluntario, Madrid, 1942. Un relato a partir de fuentes norteamericanas en Tiburcio P. CASTAÑEDA, La explosión del Maine y la guerra de los Estados Unidos con España, La Habana, 1925.

19. Santiago RAMÓN Y CAJAL, El mundo visto a los ocbenta años. Impresiones de un arteriosclerótico, Madrid, 1948, p.113; José FRANCOS RODRÍGUEZ, El año de la derrota, 1898. Memoria de un gacetillero, Madrid, 1930, p. 95. Otros ejemplos de memorias son las del mismo Conde de ROMANONES, Notas de una vida: 1860-1912, Madrid, 1945; F. de LEÓN Y CASTILLO, Mis tiempos, Madrid, 1921; o las del Marqués de LEMA, Mis recuerdos (1880-1901), Madrid, 1930.

20. El año de la derrota... Ob. Cit., p. 296.

21. "“A LA REGENERACIÓN DEL CALZADO". El historiógrafo del porvenir seguramente encontrará en este letrero una prueba de lo extendida que estuvo en algunas épocas cierta idea de regeneración nacional, y no le asombrará que esa idea, que comenzó por querer reformar y regenerar la Constitución y la raza española, concluyera en la muestra de una tienda de un rincón de los barrios bajos, en donde lo único que se hacía era reformar y regenerar el calzado" (Pío BAROJA, La busca, Madrid, Caro Ragio, 1972 ( $1^{\text {a }} \mathrm{ed}$. 1904), p. 62.

22. César SILIO Y CORTÉS, Problemas del día, Madrid, 1900, p. 4. 
tas que hay que hacerse son "¿por qué caímos?” " “Cómo podremos levantarnos?”23. Como es sabido, este estado de opinión no surge en la coyuntura de 1898 sino que comienzan a principios de la década a escucharse voces discrepantes del discurso oficial de la Restauración. En 1890 publica Lucas Mallada uno de los libros más famosos de la literatura regeneracionista: Los males de la patria En esta apelación a la República aparecen reflejados los defectos del carácter nacional: la pereza, la fantasía, la ignorancia y la falta de patriotismo. Un poco antes Valentí Almirall ya había denunciado el gobierno caciquil de una minoría y la indiferencia de la mayoría de los habitantes de una nación "prematuramente avejentada y hasta decrépita"24.

Llegamos a 1898 y Macías Picavea ofrece a los lectores sus ideas en El problema nacional. Ni la desigualdad de fuerzas ni la distancia al teatro de operaciones justifican la derrota escandalosa y vergonzosa. La explicación se encuentra en la realidad de "un país en ruinas, desorganizado, con una vida pública repleta de hondas mentiras y ficciones", una nación que "languidece en una agonía última y definitiva" mientras persiste la arrogancia y prosperidad de los directores del desastre ${ }^{25}$. Es la hora de un gran hombre, de un sujeto que emprenda la magna acción de rescate, idea en la que abunda Joaquín Costa cuando critica al régimen oligárquico y apunta la necesidad del famoso "cirujano de hierro" 26 . Medidas enérgicas que reclama también Damián Isern para salir del borde del precipicio, pidiendo frente a la debilidad de los gobernantes el fortalecimiento del Ejército como garante del orden social ${ }^{27}$.

Aunque los republicanos Costa y Picavea y el reaccionario Isern coinciden en algunos de los remedios propuestos no todo el pensamiento regeneracionista comulga de los mismos principios. Mención aparte merece Luis Morote, quien se declara partidario de una democracia verdadera y señala, en contra del título del conocido artículo de Silvela, que España tiene pulso, el pulso de las fuerzas sociales democráticas que empiezan a sacudirse el virus de la derrota ${ }^{28}$. A título de inventario podemos citar por último otros ensayos publicados en estos años posteriores al "desastre" donde se reparten culpas entre las clases dominantes y las masas populares. Vidal Fité y Gustavo La

23. Ibid. p. 6 .

24. Lucas MALLADA, Los males de la patria y la futura revolución española, Madrid, Fundación Banco Exterior, 1989; y Valentí ALMIRALL, España tal como es (La España de la Restauración), Madrid, $1972\left(1^{a}\right.$ ed. 1886), p. 154. Otras obras anteriores al "desastre": José Tomás SALVANY, España a fines del siglo XIX, Madrid, 1891; Miguel de UNAMUNO, En torno al cataclismo, Madrid, 1961 (publicado en La España Moderna en 1895); y Gumersindo de AZCÁRATE, El régimen parlamentario en la práctica, Madrid, 1892.

25. Ricardo MACIAS PICAVEA, El problema nacional (bechos, causas y remedios), Madrid, Seminarios y Ediciones, 1972 ( $1^{\text {a }}$ ed. 1898) pp. 115-116.

26. En 1898 Joaquín COSTA publica Colectivismo agrario en España. Doctrinas y bechos; y en 1901 escribe Oligarquía y caciquismo como la forma actual de gobierno en España, memoria de la encuesta que promovió el Ateneo de Madrid. Los informes y testimonios de dicha encuesta recogidos por Alfonso ORTI, Oligarquía y caciquismo como la forma actual de gobierno en España. Urgencia y modo de cambiarla, Madrid, Ed. Revista de Trabajo, 1975, vol. II (1ª ed. 1902). Una selección de los trabajos de Costa en Oligarquía y caciquismo, colectivismo agrario y otros escritos, Madrid, Alianza, 1969.

27. Damián ISERN, Del desastre nacional y sus causas, Madrid, 1899; y De la defensa nacional, Madrid, 1901

28. Luis MOROTE, La moral de la derrota, Madrid, 1900; Sagasta, Melilla, Cuba, París, 1908; y El pulso de España, Madrid, 1904. El artículo de Francisco SILVELA "Sin pulso", en El Tiempo, 16-8-1898, recogido en Artículos, discursos, conferencias, cartas, Madrid, 1922. 
Iglesia insisten en el marasmo y la apatía ${ }^{29}$; Santiago Alba subraya la superioridad de los anglosajones $^{30}$; el Doctor Madrazo confia en las clases medias para el resurgir social ${ }^{31}$; Tomás Jiménez Valdivielso hace hincapié en el atraso secular de la nación ${ }^{32}$; y en parecidos términos podríamos hablar de las páginas escritas por Rafale Labra, Angel Gavinet, Ramiro de Maeztu,A Royo Villanova, o J. Rodríguez Martínez, hasta llegar a las obras más tardías de Julio Senador Gómez ${ }^{33}$. Estos son "los hombres que atronaban en la plaza pública al finar el siglo", los teóricos que dibuja Azaña paseándose por los escombros del "desastre" cuando hace balance de su obra y anota que las cosas que les hacían rechinar los dientes se mantienen en pie tres décadas más tarde ${ }^{34}$.

\section{CiNCUENTA AÑos DESPUÉS: El RESURGIR DE LA RAZA}

En 1948, con motivo el cincuentenario del "desastre" la revista Arbor dedica un número entero a la revisión de lo ocurrido en el fin de siglo. Ahora sí que podemos decir que las cosas han cambiado bastante. En medio ha quedado la experiencia de seis años de república y el impacto de una larga guerra civil que abre paso a la dictadura del general Franco, uno de los militares sublevados para restaurar el orden y acabar con el amplio proceso de movilización social que en buena medida arranca en los días del 98. En el monográfico citado publica un artículo Melchor Fernández Almagro en el que repasa las actitudes populares desde el patriotismo inconsciente de los primeros años hasta la decepción, la angustia general y la ola depresiva que dejó anonadados a los españoles sin energías y sin medios materiales para intentar nada.Además, la Monarquía conservaba su prestigio y no existía un instrumento capaz de hacer una revolución. Concluye el último párrafo del estudio relacionando la crisis del 98 con la llegada de la dictadura de Primo de Rivera en 1923, la proclamación de la República en 1931 y el estallido de la "guerra de liberación" en 1936:

"Frutos tardíos del malestar, de las inquietudes, de las contradictorias ansias a que el Desastre diera lugar, poniéndolo todo, por lo pronto, en entredicho, sometiéndolo a implacable revisión: desde lo político y social hasta lo literario y cultural" ${ }^{35}$.

29. Vital FITE, Las desdichas de la patria, Madrid, 1899; y Gustavo LA IGLESIA, El alma española. Ensayo de una psicología nacional, Madrid, s.f.

30. Santiago ALBA, prólogo a la obra de Edmundo DEMOLINS, En qué consiste la superioridad de los anglo-sajones, Madrid, 1899. Ver también las reflexiones publicadas posteriormente en Problemas de España, Madrid, 1916.

31. Doctor MADRAZO, ¿El pueblo español ba muerto? Impresiones sobre el estado actual de la sociedad española, Santander, 1903.

32. John CHAMBERLAIN (seudónimo de Tomás JIMÉNEZ VALDIVIELSO) El atraso de España, Valencia, 1904.

33. Rafael María de LABRA, El pesimismo de última bora, Madrid, 1899; Ángel GAVINET, Idearium español, Madrid, 1957 ( $1^{\mathrm{a}}$ ed. 1897); Ramiro de MAEZTU, Hacia otra España, Madrid, Rialp, 1967 (1 ${ }^{\mathrm{a}}$ ed. 1899); A. ROYO VILLANOVA, La regeneración y el problema político, Madrid, 1899; J. RODRÍGUEZ MARTÍNEZ, Los desastres y la regeneración de España, La Coruña, 1899; Julio SENADOR GÓMEZ, Castilla en escombros, Madrid, 1978 ( $1^{2}$ ed. 1915).

34. Manuel AZAÑA, $O b$. Cit. pp. 252-254.

35. Melchor FERNÁNDEZ ALMAGRO, "Reacción popular ante el Desastre", Arbor, 36, dic. 1948, p. 397. Ver también, editado en el mismo año, En torno al 98. Política y literatura, Madrid, Jordán, 1948. 
No es éste el único autor que destaca el "glorioso alzamiento" como el momento de resurrección del espíritu nacional postrado en la catástrofe de la guerra colonial.Galindo Herrero escribe pocos años después un libro donde recoge cartas y testimonios de antiguos combatientes en Cuba y Filipinas. Lo interesante no es tanto la descripción de los sucesos de la guerra como la valoración general del momento histórico. En este sentido, el negro crespón de luto que el 98 pone a los colores de la patria no es sino el resultado de todos los errores anteriores del "período orgiástico liberal que lo precede". Desde entonces dicha fecha "araña duramente en los pechos de los españoles como acerado cilicio que nos recordara constantemente lo que fuimos y el por qué lo perdimos"36. Faltaba desde entonces una reacción viril que acabara con la "charca política" y pusiera en orden a España, reacción que emprenderán los nietos del 98 heroico cuando cumplen el destino de su generación sumándose a la Cruzada del 18 de julio de 1936:

"No fue el 18 de julio un movimiento espasmódico de negación de una situación ilegal, un anti sin contenido. (...) Y si todos aspiraban a una pacificación de los espíritus, a la vuelta a una situación legal en que se respetaran todos los derechos y se abriera amplio cauce a nuestra tradición y creencias católicas, todos soñaban también con encontrar nuevos caminos a la Patria, en los que recuperara su puesto de honor en el mundo y por los que fuera fiel a su destino misionero (...) Ninguno de los voluntarios que en los primeros días tomaron en sus manos casi infantiles el fusil pensaron en intereses propios o ajenos; sólo el ideal los guiaba. (...) A quienes les faltó el coraje suficiente para cantar agriamente por los campos la verdad de España, son indignos de nuestra generación y de la época que les tocó vivir. Por eso están con los del 98 que no fueron a la guerra" ${ }^{37}$.

Los colores de la bandera nacional vuelven a brillar de nuevo recuperando su prestigio labrado en siglos de gestas imperiales. España retorna a su destino histórico en lo universal libre de los políticos que la humillaron, de los agitadores de oficio y los escritores de fin de siglo de "ideas caducas y disolventes" que están bien en el olvido:" ¿Por qué airearlas si llevan en sí mismas el germen de la muerte y sólo son capaces de sostenerse en pie con el rodrigón de la inconsciencia ajena?" 38 . La nostalgia del pasado imperial, de la raza fecundadora de mundos, se recrea ahora en una nueva mirada a las antiguas colonias a través del concepto de hispanidad y de la difusión de la idea de la Madre Patria, protectora de sus antiguos hijos en cuyo favor había sacrificado su esplendor y poderío

"volcándolos a torrentes en América y quedándose en la depauperación lenta y heroica de la madre cuya vida sorbe el hijo agarrado a las fuentes de sus pechos, en la postración dulcísima del que, guardando sólo la honra, todo lo dio..."39.

36. Santiago GALINDO HERRERO, El 98 de los que fueron a la guerra, Madrid, Editora Nacional, 1955, p. 42.

37. Ibid, p. 113 .

38. "La intolerable resurrección del 98", Acies. Semanario de Orientación y Propaganda religiosomoral, Logroño, 3-IV-1945, $\mathrm{n}^{\circ} 283$.

39. Agustín SERRANO DE HARO, España es así, Madrid, Ed. Escuela Española, 1965 (1ª ed. 1946), p. 181. En el mismo libro de lecturas juveniles se ensalza el Día de la Hispanidad, cuando resuena en todo el mundo un canto de amor y gratitud "en homenaje a España, progenitora de naciones, a las cuales ha dado, con la levadura de su sangre y con la armonía de su lengua, una herencia inmortal” (p. 160). 
La visión que en los libros de texto y de lecturas históricas se ofrece del Desastre de 1898 es la de los bravos soldados españoles vencidos por los usurpadores norteamericanos gracias al abandono de los débiles gobiernos liberales:

"¡Cuántas revueltas, luchas civiles y sociales, desórdenes públicos y atropellos llenan nuestra Historia Contemporánea! Todos esos males proceden de habernos olvidado del espíritu imperial católico de nuestros mejores tiempos y de haber admitido el liberalismo, la masonería y el separatismo que nos han conducido al borde la ruina" ${ }^{40}$.

De la "villanía del despojo más inicuo que vieron los tiempos", ejercido sobre un país "empobrecido, inerme y decadente", sólo se salvan gestas heroicas como las del héroe de "Cascorro" Eloy Gonzalo; el guardamarina Saralegui que en Santiago de Cuba muere contento besando el escapulario de la Virgen del Carmen regalado por sus padres; los defensores del cerro de Caney al mando del general Vara de Rey; o la entereza ante el sacrificio del Almirante Cervera ${ }^{41}$. La victoria de las milicias españolas en el "Movimiento salvador" que emprendieron el 18 de julio de 1936 ha restañado las heridas de 1898 con un gran caudal de energía y fortaleza de ánimo:

"Niño: de España se dijo en otro tiempo que era un pueblo sin pulso: ya has visto que no es cierto. Cuando se lucha por Dios y por la Patria, el pueblo español vibra de arriba a abajo como un avión que vuela camino de la gloria" ${ }^{42}$.

Una de las instituciones creadas al terminar la guerra civil para difundir las ideas hispanistas y neoimperialistas, el Consejo de la Hispanidad, encargó al director de cine José Luis Sáenz de Heredia la producción de la película Raza a partir de un guión firmado por Jaime de Andrade. Como es conocido, tras este seudónimo se esconde la pluma de Francisco Franco. Estrenado en 1942, el filme justifica la sublevación de los militares contra la República en 1936 y destaca la figura protagonista de José Churruca, héroe de la guerra que logra sobrevivir hasta a un pelotón de fusilamiento y acaba participando en el desfile de la Victoria. De forma muy significativa la primera parte de la obra transcurre en los días de la guerra hispano-americana. Se afirma que España "se asemeja a un barco de sin gobierno" y así se aprecia en la escena en la que un grupo de Jefes militares comentan los acontecimientos del conflicto colonial:

\section{CHURRUCA.- ¿Murmuraban ustedes de Ultramar?}

EL JEFE DE E. M.- Sí, está todo tan liado. ¿No ha estado usted por Filipinas? ¿Qué nos cuentan de allá?

CHURRUCA.- Poco. En Filipinas... las mismas perturbaciones fomentadas por el extranjero, la perenne rebeldía de las gentes de Joló. Las intrigas extranjeras y..., lo que es peor, la invasión de la masonería (...)

EL COMANDANTE DE INFANTERÍA DE MARINA.- Algo parecido a lo de Cuba, aunque esto aún es más serio (...) Abandonados de España, mejor dicho, prisioneros

40. EDELVTVES, Historia de España. Primer grado, Zaragoza, Ed. Luis Vives, 1949, p. 114.

41. Vicente HERNANDO y Víctor FERNÁNDEZ DE LARREA, Lecturas bistóricas, Madrid, Ed. S.M., 1964 , pp. 164 y 193-198.

42. HIJOS DE SANTIAGO RODRÍGUEZ, Héroes. Libro escolar de lectura, Burgos, 1939, p. 247. Acerca de la nostalgia del mito imperial, ver el trabajo de Martin BLINKHORN, "Spain":The "Spanish Problem" and The Imperial Myth", Journal of Contemporary History, 15, 1980, pp. 5-25. 
de España.Yo he leído, en el Estado Mayor del Capitán General de la Isla, cartas que destilaban sangre. «El Gobierno no quiere aventuras...; hay que contemporizar...; no se pueden enviar más hombres...; la guerra no es popular..."

OTRO JEFE (Con energía) - ¿Qué han hecho para que lo sea? ¿Sabe siquiera el país lo que aquello representa? ¡Cuánta vergüenza!

EL JEFE DE E.M.- Y, al final, sin armas, sin efectivos, sin política exterior, aislados del mundo, tendremos la culpa los militares ${ }^{43}$.

Un poco más adelante, en la cámara de oficiales del barco insignia de la flota española en aguas de Santiago de Cuba, se describe la reunión del Almirante Cervera con los Comandantes de los barcos antes de salir hacia una derrota segura:

"La orden es terminante: hacerse a la mar y enfrentarse con la escuadra enemiga.

(Los marinos se miran con inquietud)

UN JEFE.- Mi General...

ALMIRANTE CERVERA (Templándolos con su mirada).- Nada me digan. Las razones desaparecen ante el deber. Sólo nos queda obedecer, cumplir como buenos, que en medio de todo no vale la pena sobrevivir a esta vergüenza. La Historia sabrá juzgarnos. No hay sacrificio estéril; del nuestro de hoy saldrán las glorias del mañana. Señores: Listos para zarpar. ¡Viva España!

TODOS (Con energía).- ¡Viva!" ${ }^{4}$.

Las últimas páginas del guión narran el desfile de la Victoria.A la cabeza figuran los representantes de la Armada emocionando el corazón de un viejo Almirante que exclama: “iPor fin! ¡Cómo lo anhelaba! ¡Romper nuestras cadenas! ¡Lograr mi revancha!”. Un niño dice que quiere ser marino y el mismo militar le replica: "Lo serás; pero con honra y barcos". Es el final apoteósico en el que resurge la estirpe de los almogávares, "el manantial inagotable de nuestra raza ibera" ".

\section{Hacia el Centenario}

Después de estos primeros años de propaganda franquista el tema del "desastre" de 1898 no ha dejado de ser objeto de atención para escritores e historiadores. Desde una perspectiva conservadora, aunque utilizando fuentes muy diversas, el estudio más importante -hoy se sigue citando en la mayoria de los trabajos- es la Historia politica de la España contemporánea de Melchor Fernández Almagro, extensa crónica de la Restauración desde la Revolución de 1868 hasta la jura de Alfonso XIII en $1902^{46}$. Otros

43. Jaine de ANDRADE, Raza. Anecdotario para el guión de una película, Madrid, Fundación Francisco Franco, 1982 ( $1^{\mathrm{a}} \mathrm{ed} .1942$ ), pp. 39-40.

44. Ibid, p. 52.

45. Ibid, pp. 197-198. Un análisis de la obra, donde se destacan las relaciones entre los personajes de la novela y la propia familia de Franco, en Román GUBERN, Raza: un ensueño del general Franco, Madrid, Ediciones 99, 1977. La primera versión de la película de 1941 fue reformada en una posterior de 1949 donde se suprimen las escenas de carácter fascista y antiamericano. Ver, sobre este aspecto, Ramiro CRISTÓBAL, "El general Franco censuró al caudillo", El País, 14-1-1996, pp. 14-15 del suplemento del domingo.

46. Melchor FERNÁNDEZ ALMAGRO, Historia política de la España contemporánea, Madrid, Alianza, $1972\left(1^{2}\right.$ ed. 1956), 3 vols. 
análisis interesantes, pese a que no aportan variaciones sustanciales respecto a las interpretaciones conocidas, son los de José Cepeda Adán sobre el 98 madrileño; los comentarios de Carlos Martínez de Campos acerca del papel desempeñado por la Reina Regente; las anotaciones de José Fernández-Rúa de la "lacra" de la "desgana nacional" que se precipitaría cuarenta años más tarde en la guerra civil; o los posteriores relatos más descriptivos de autores como Pablo de Azcárate y Rafael Pérez Delgado $^{47}$.

Los primeros trabajos que inauguran otras vías de interpretación del "desastre" son los de los profesores Pavón y Jover Zamora, quienes miran más allá del solar patrio y descubren que Francia con sus reveses en Egipto, Portugal con el fin sus sueños expansionistas e Italia con su derrota en Abisinia sufrieron también sus propias crisis del 98. En efecto, la crisis de fin de siglo debe ser considerada también como un acontecimiento internacional dentro del marco de la época del imperialismo y de la pugna de las naciones industrializadas por el dominio de los mercados mundiales ${ }^{48}$. Posteriormente han abundado en el tema de la política exterior y la situación internacional Rosario de la Torre del Río y Cristóbal Robles Muñoz ${ }^{49}$. Desde estas nuevas perspectivas, los estudios sobre la guerra colonial han introducido nuevos factores de análisis económicos, sociales y políticos. A este respecto, el mejor libro de conjunto sigue siendo el de Carlos Serrano sobre el final del Imperio, al que se pueden añadir las apreciaciones sobre el poder político y las estructuras sociales del Manuel Tuñón de Lara, algunas aportaciones de interés como las de José Varela Ortega o Joseph Smith o el reciente estado de la cuestión de Mariano Esteban de Vega ${ }^{50}$.

Quizás el tema que más tempranamente recibió una atención seria por parte de escritores e historiadores fue el de la literatura y el pensamiento de fin siglo, desde la creación de la generación del 98 hasta los ensayos regeneracionistas. Sin pretender

47. José CEPEDA ADÁN, "El 98 en Madrid”, Temas madrileños, IX, Madrid, Instituto de Estudios Madrileños, 1954, pp.23-35; Carlos MARTÍNEZ DE CAMPOS Y SERRANO, La Reina Cristina y el Desastre, Madrid, 1959; José L. FERNÁNDEZ-RÚA, 1898: Cuba y Filipinas, Madrid, 1959 (entrecomillados en p. 4); Pablo de AZCÁRATE, La guerra del 98, Madrid,Alianza, 1968; y Rafael PÉREZ DELGADO, 1898, el año del Desastre, Madrid, Tebas, 1976.

48. Jesús PABÓN, "El 98, acontecimiento internacional", Días de ayer, Barcelona, Alpha, 1963; y José María JOVER ZAMORA, Política, diplomacia y bumanismo popular en la España del siglo XIX, Madrid, Turner, 1976, y Teoría y práctica de la redistribución colonial, Madrid, 1979.

49. Rosario de la TORRE DEL RÍO, Inglaterra y España en 1898, Madrid, Eudema, 1988, y "Los noventa y ocho" " "El noventa y ocho español", en La víspera de nuestro siglo, Historia Universal Siglo XX, Madrid, Historia $16, \mathrm{n}^{\circ}$ 1, pp. $65-84$ y 97-110 respectivamente; y Cristóbal ROBLES MUÑOZ, 1898 : Diplomacia y opinión, Madrid, C.S.I.C., 1991.

50. Carlos SERRANO, Final del Imperio. España, 1895-1898, Madrid, Siglo XXI, 1984; Manuel TUÑÓN DE LARA, Poder y sociedad en España, 1900-1931, Madrid, Espasa-Calpe, 1992 (1ª ed. 1984); José VARELA ORTEGA, "Aftermath of Splendid Disaster: Spanish Politics before and after the Spanish American War of 1898", Journal of Contemporary History, 15, 1980, pp. 317-344; Joseph SMITH, "The "Splendid Little War" of 1898:A Reappraisal”, History, The Journal of the Historical Association, vol. 80, ${ }^{\circ} 258,1995$, pp. 22-37; y Mariano ESTEBAN DE VEGA, "La crisis del 98 en la crisis de la Restauración”, en Chris Wickham, Henry Kamen, Elena Hernández Sandioca y otros, Las crisis en la Historia, Salamanca, 1995, pp. 201211. Otras narraciones de la guerra en P. S. FORNER, La guerra bispano-cubana-americana y el nacimiento del imperialismo norteamericano, Madrid, Akal, 1975; L. NAVARRO GARCÍA, La independencia de Cuba, Madrid, Mapfre, 1991; J. BARÓN FERNÁNDEZ, La guerra hispano-americana de 1898, La Coruña, 1993; o la monografia del CESEDEN, La presencia militar española en Cuba (1868-1895), II Jornadas de Historia Militar, Madrid, Ministerio de Defensa, 1996. 
abordar la extensa bibliografia que disponemos podemos subrayar los primeros estudios de Jose Luis Abellán y Enrique Tierno Galván o las obras de Jacques Maurice y Carlos Serrano, Manuel Tuñón de Lara y Juan Sisinio Pérez Garzón ${ }^{51}$.

Además de la valoración del papel desempeñado por los intelectuales, el análisis de la reacción popular ante el "desastre" también ha sido revisado por la historiografia social en los últimos años. Frente a la imagen de apatía, letargo e indiferencia del pueblo inculto e irracional que pacientemente se dejaba llevar al matadero y pagaba con resignación las contribuciones, se ha destacado la relevancia de la protesta popular frente a las quintas y la extensión de los motines contra la carestía de las subsistencias y el impuesto de consumos que se producen en los años de fin siglo.Así lo han hecho, entre otros, Carlos Serrano, Nuria Sales de Bohigas, y Elena Hernández Sandioca ${ }^{52}$.

Los ejemplos de prófugos, desertores y amotinados cuestionan o matizan al menos la idea de una sociedad desmovilizada y completamente inerme frente al entramado caciquil montado por los gobernantes de la Restauración. Es cierto, por una parte, que los temores del Régimen hacia una posible revolución como reacción frente al "desastre" resultan infundados. En 1902 Alfonso XIII recoge la Corona de manos de la Regente y los partidos dinásticos seguirán gobernando sin demasiados problemas por lo menos hasta 1917. Sin embargo, por otro lado, la crisis del 98 no dejará de pasar su cuenta al Estado y en los primeros años del siglo XX los embrionarios partidos y movimientos de oposición alcanzarán un notable desarrollo. En las jornadas de la Semana Trágica de 1909 o en los conflictivos años de la $1^{a}$ Guerra Mundial escucharemos ecos de las voces de queja contra las injusticias del sistema de reclutamiento, el precio de los alimentos de primera necesidad o la presión fiscal que habían conseguido hacerse oir en la crisis de fin de siglo. Los casos estudiados de Asturias, Málaga, Murcia,

51. José Luis ABELLÁN, Sociología del 98, Barcelona, 1973; Enrique TIERNO GALVÁN, Costa y el regeneracionismo, Barcelona, 1961; Jacques MURICE y Carlos SERRANO, J. Costa: Crisis de la Restauración y populismo (1875-1911), Madrid, Siglo XXI, 1977; Manuel TUÑÓN DE LARA, España: la quiebra de 1898 (Costa y Unamuno en la crisis de fin de siglo), Madrid, Sarpe, 1986, y Medio siglo de cultura española, 1885-1936, Barcelona, Bruguera, 1982; Juan Sisinio PÉREZ GARZÓN, Luis Morote, la problemática de un republicano (1862-1923), Madrid, Castalia, 1976. Una valoración general sobre el movimiento regeracionista en Joseph HARRISON, "The Regenerationist Movement in spain after the disaster of 1898", European Studies Review, 9, 1979, pp. 1-27. Por último, acerca de la literatura de 1898 existe la recopilación de poesías de Carlos BARRÓN, Cancionero del 98, Madrid, Cuadernos para el Diálogo, 1974; y las obras más generales de Lily LITVAK, Transformación industrial y literatura en España (1895-1905), Madrid, Taurus, 1980, y de José-Carlos MAINER, La Edad de plata (1902-1939), Ensayo de interpretación de un proceso cultural, Madrid, Cátedra, 1987.

52. Carlos SERRANO, Le Tour du peuple, Madrid, Casa de Velázquez, 1987; "Guerra y crisis social: los motines de mayo del 98", Estudios de Historia de España, Homenaje a M.Tuñón de Lara, Madrid, 1981, vol. I, pp. 439-449; "Prófugos y desertores en la guerra de Cuba", Estudios de Historia Social, 22-23, 1982, pp. 253-278; y 1900 en España, Madrid, Espasa-Calpe, 1991 (coautor junto con Jacques Maurice). De Nuria SALES DE BOHÍGAS reseñar "Servicio militar y sociedad en la España del siglo XIX", en Sobre esclavos, reclutas y mercaderes de quintas, Barcelona,Ariel, 1974; y de Elena HERNÁNDEZ SANDIOCA, "Higiene y sociedad en la guerra de Cuba (1895-1898). Notas sobre soldados y proletarios", Estudios de Historia Social, 5-6, 1978, pp. 361-384. La importancia de la protesta popular señalada también recientemente por Sebastian BALFOUR, "Riot, Regeneration and Reaction: Spain in the Aftermath of the 1898 Disaster", The Historical Joumal, 38, 2 (1995), pp. 405-423, y dos trabajos generales sobre las quintas en el siglo XIX: Fernando PUELL DE LA VILLA, l soldado desconocido. De la leva a la "mili" (1700-1912), Madrid, Biblioteca Nueva, 1996, y Albino FEIJOO GÓMEZ, Quintas y protesta social en el siglo XIX, Madrid, Ministerio de Defensa, 1996. 
Navarra o La Rioja dan fe, desde el marco de la historia local y regional, de la importancia de estas acciones colectivas populares en el cambio de $\operatorname{siglo}^{53}$.

Cumplido ya un siglo desde el inicio de la guerra de Cuba la llegada del centenario ha propiciado la aparición de numerosos artículos y libros que abordan el estudio del "desastre" mostrando diferentes preocupaciones y puntos de vista. Entre las contribuciones más interesantes hay que subrayar la historia de las relaciones entre la "perla de las Antillas" y la metrópoli del cubano Manuel Moreno Fraginals, una narración desde la colonización hasta una independencia que no significó ruptura;.el recuento de Sebastian Balfour de las respuestas ante el 98 de los diferentes grupos sociales (militares, clases medias, sectores populares y nacionalistas periféricos); la visión cultural de la España de fin de siglo de Inman Fox; o la publicación de las diversas ponencias y comunicaciones de un congreso sobre los orígenes y antecedentes de la crisis del $98^{54}$. Se ha abandonado la visión agónica y catastrofista de la pérdida de las colonias y en vez de centrar toda la atención en los días de la derrota se presentan los hechos de 1898 dentro de un amplio proceso de cambios sociales, políticos y económicos que tienen lugar en los años centrales de la Restauración y que no afectan exclusivamente a España. Además, sin detenerse mucho en el relato de las operaciones militares ni repetir el florilegio de llantos regeneracionistas se esbozan problemas más generales como la crisis de identidad nacional o el crecimiento de la oposición al sistema político dando cabida a otras voces y percepciones.

Muchas veces la proximidad del aniversario de un hecho histórico es utilizada para deformar la memoria del pasado, para celebrar el presente o para difundir el buen nombre de las instituciones y entidades organizadoras. Desde este punto de vista el centenario del "desastre" del 98 no es una excepción y se multiplican los congresos, cursos, seminarios y publicaciones -éstas páginas son un ejemplo- que rinden honores a la efemérides, con la salvedad de que en esta ocasión lo que se conmemora es una derrota, un acontecimiento dificil de presentar. Sin embargo, pese a los recelos apuntados, es pertinente y puede ser interesante aprovechar la ocasión del centenario para mostrar en su escaparate temas y protagonistas marginados y para introducir los grandes problemas de la historia de Contemporánea de España.

53. Jorge URÍA GONZÁLEZ, Asturias y Cuba en torno al 98, Barcelona, Labor, 1994; Fernando ARCAS CUBERO, "Málaga en el 98. Repercusiones sociales de la guerra hispano-cubano-americana", Baética, Málaga, 12, 1989, pp. 281-298; M Teresa PÉREZ PICAZO, Oligarquía urbana y campesinado en Murcia, 1875-1902, Murcia, 1979; J.F. KARASUSAN y R. GATIA, "Navarra y la Guerra de Independencia Cubana: política institucional y actitud popular", Príncipe de Viana, Anejo 13, 1991, pp. 413-422; y Carlos GIL ANDRÉS, Protesta popular y orden social en La Rioja de fin de siglo, Logroño, Instituto de Estudios Riojanos, 1995.

54. Manuel MORENO FRAGINAIs, Cuba/ España. España/ Cuba. Historia común, Barcelona, Crítica, 1995; Sebastian BALFOUR, El fin del Imperio español (1898-1923), Barcelona, Crítica, 1997; Inman FOX, La invención de España. Nacionalismo liberal e identidad nacional, Madrid, Cátedra, 1997; Juan PABLO FUSI y Antonio NIÑO (eds.) Vísperas del 98. Orígenes y antecedentes de la crisis del 98, Madrid, Biblioteca Nueva, 1997, y Antes del "desastre": orígenes y antecedentes de la crisis del 98, Madrid, Universidad Complutense, 1996 (ponencias y comunicaciones, respectivamente, del Congreso Internacional del mismo título organizado por Dpto. de Historia Contemporánea de la Universidad Complutense, Madrid, 23-25 de noviembre de 1895). 